\title{
Ultimate limit state design of retaining walls with numerical methods
}

\author{
G. Katsigiannis \\ Arup Geotechnics and University College London, London, UK \\ P. Ferreira \& R. Fuentes \\ University College London, London, UK
}

\begin{abstract}
This paper presents a comparison between the results obtained from simple empirical methods, and full FE using Eurocode 7 (EC7) for the design of supported excavations. It shows the influence of the current different EC7 implementation strategies for the use of partial material factors when using Design Approach 1, both for Combination 1, where the action effects are factored at the end of the calculations, and also for Combination 2, where the soil strength parameters need to be factored and procedures are less clear. The influence of different factors in the results is highlighted for structural forces in cantilever and supported walls with increasing excavation depth and number of props. It shows the differences in prop loads obtained from FEM and empirical approaches and illustrates the difficulties that designers face when using EC 7.
\end{abstract}

\section{INTRODUCTION}

Nowadays, the increasing demand for underground infrastructure and basements in urban environments highlights the need for achieving more economic and safe design of retaining walls. The requirement of limiting ground movements and movements of adjacent structures and utilities (i.e. serviceability limit states) becomes an important factor; however, there is also the need to ensure that no failure of the support system occurs. Failures are rare but do occur (Twine \& Roscoe, 1999).

Design of retaining walls in compliance with Eurocode 7 Design Approach 1 (DA1), require Ultimate Limit State checks for two Combinations or sets of partial factors. The merits of DA1 are discussed in detail by Simpson (2007). Applying Combination 1 (DA1-1) with Finite Element Methods (FEM) requires factoring the action effects at the end of the calculations as the earth pressures cannot be factored from the beginning. Combination 2 (DA1-2) is well suited to FEM as it requires factoring the soil strength parameters which are the input parameter of commonly used constitutive models. However, Eurocode 7 gives no guidance on when to apply the material partial factors. Current practice suggests two different strategies that, quite often, give different results in terms of design bending moments and prop forces (Simpson, 2012). This paper compares different factoring methods, for cantilever and multi prop walls, while the influence of different factors on the resulting discrepancies is investigated.

\section{DESIGN METHODOLOGY}

\subsection{Finite Element Methods and Eurocode 7}

FEM have been traditionally used in geotechnical engineering to obtain deformations and check for
SLS. For ULS the designers used to simply factor the structural forces (bending moments, prop forces etc.) at the end of the calculations. However, the requirements are now different in light of EC7. There are still a number of issues that need further research before the ULS design can be routinely performed with FEM. Simpson (2012) and Simpson \& Junaideen (2013) give a good review of all these challenges associated with the ULS design with FEM.

\subsection{Material factoring strategies}

Two main different ways to apply partial factors in FEM have been suggested in the literature (Simpson, 2012). In Strategy 1, the partial factors are applied to soil strength parameters from the beginning and the analysis is performed with factored values of strength (design values in the EC7 terminology). Conversely, in Strategy 2, calculations are performed with characteristic values and at critical stages the material parameters are factored to their design values to check that no ULS has been reached. A good description of the two strategies has been given by Simpson (2012) (see Figure 1).

While Strategy 1 has the obvious advantage of simplicity, most authors prefer using Strategy 2. The reason for this is that applying partial factors from the beginning results in unreasonable or optimistic effects later. Moreover, in many cases, the designer can perform SLS and ULS checks with only one analysis, by employing Strategy 2 . The caveat being that this only applies when no changes in geometry, water levels or surcharge loads are needed. Finally, another advantage of Strategy 2 is that it facilitates the use of the automatic c-phi reduction technique (Simpson, 2012), which is well established among the geotechnical engineering community. 


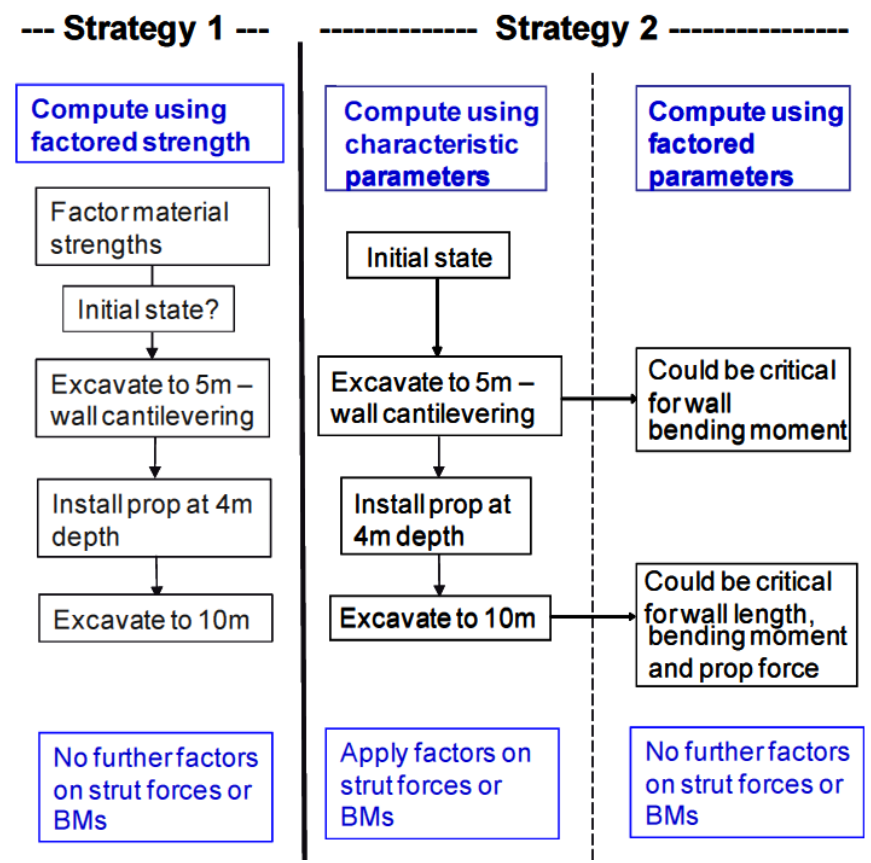

Figure 1. Strategies for analysis of staged construction (after Simpson, 2012)

A few authors in the past compared the different strategies of applying partial factors in staged excavation problems with FEM. Bauduin et al. (2000) found that, factoring the material parameters only at critical stages (Strategy 2) resulted in slightly higher design values of the internal forces in structural members for a singly supported sheet pile wall. They also found that DA1-1 was less critical compared to both strategies of DA1-2. The authors also considered a multi-propped diaphragm wall, obtaining different design prop forces and bending moments from the two strategies. Simpson and Yazdchi (2003) studied a staged excavation for a multipropped wall and concluded that DA1-1 is more critical when the length of the wall has not been optimised by carrying out a stability analysis. Expanding on this, Simpson \& Driscoll (1998) observed that for specific cases, Strategy 2 can give more onerous results. Schweiger (2005) considered a single strutted wall with a staged excavation and obtained quite similar results for both DA1-2 Strategies, where Strategy 2 resulted in only slightly higher design values. Repeating the calculations with a surcharge, the same conclusions were drawn. In all cases DA11 gave lower design values. Simpson \& Hocombe (2010) used the case study of the Florence High Speed Station to compare the two strategies, concluding that applying factors at discrete stages (DA1-2 Strategy 2) mainly governs the design.

While most authors seem to agree that Strategy 2 might give more onerous results, this may not always hold and therefore, there is a need for a better understanding of the resulting discrepancy.

\subsection{Automatic c-phi reduction}

Many geotechnical engineering software packages have included a facility called automatic $c-\varphi$ reduction. By employing this technique the user can drive the system to failure, at discrete stages, by reducing stepwise the material strength properties and obtain the corresponding material safety factor. If the factors are greater or lower than those required by the code, the designer can revise the geometry and perform again the analysis (Simpson, 2012). Most commercial packages use the automatic strength reduction with the simple Mohr Coulomb soil model, while Potts \& Zdravkovic (2012) have recently proposed a method that can be applied with both simple and more advanced soil models.

This is an interesting approach as it enables the designer to get an estimate of economy at each critical stage. However, EC7 does not suggest dealing with fully mobilised mechanisms but ensuring that failure is sufficiently unlikely to occur for the given combinations of factors. The main disadvantage of the stepwise strength reduction is that it gives no useful information about the design structural force values. EC7 requires that the designer should check against both GEO and STR Ultimate Limit States. Hence, it seems that the stepwise strength reduction is most useful when used as an extra analysis to identify the critical failure mode and the margin of safety. However, it should be clear that this is not an EC7 requirement.

\subsection{Numerical and empirical methods for multi- propped retaining wall design}

For multi-propped walls there are a number of empirical graphs that can be used to obtain the prop forces. Traditional methods (Terzaghi \& Peck, 1967 and Peck, 1969) are simple to use and have been widely adopted in practice. They are based on field measurements of prop loads and provide the designer with conservative lateral earth pressure distributions.

CIRIA C517 (Twine \& Roscoe, 1999), enhancing Terzaghi's work and making it more relevant to UK practice, suggests the use of the Distributed Prop Load (DPL) method, based on 81 case histories and field measurements of prop loads. Soils are classified in 4 classes named A, B, C and D, referring to normally consolidated and slightly overconsolidated clays, heavily overconsolidated clays, granular soils and mixed soils respectively. A distinction is also made between flexible (e.g. sheet pile) and stiff (e.g. diaphragm and bored pile) walls. DPL is not the real lateral stress distribution but gives values of characteristic prop forces unlikely to be exceeded for any temporary system in a similar excavation (Twine \& Roscoe, 1999). There are also a number of conditions that the designer should check before using the 
empirical graphs (geometry, surcharge, sufficient toe embedment, etc).

BS8002 (1994) for multi-propped walls simplistically recommends the use of Peck's diagrams without mentioning how they should be used for ULS and SLS calculations.

\subsection{Water pressures and limit state design}

According to Simpson et al. (2011) the water pressures can have significant effect in the geotechnical design and they involve high uncertainties. Unexpected variation can drive the system to failure. Hence, the designer should always consider the worst water pressures that could occur and not just rely on the factors of safety. Engineering justice and expertise is essential especially in situations where the water pressures might be critical for the design (Simpson et al., 2011).

BS8002 requires that "the water pressure regime used in the design should be the most onerous that is considered to be reasonably possible" (BS8002, 1994).

EC7 (EN1997-1, 2004) suggests that a safety margin in terms of water pressures can be applied either by modifying the water table level or by factoring directly the water pressures. As water pressures cannot be factored with FEM, the designer should consider the water table level as the most unfavourable during the design lifetime of the structure for ULS and as the most unfavourable under normal conditions for SLS (EN1997-1, 2004).

EC7 Evolution Group 9 (EG9) which is working on water pressures has recently proposed alternative definitions, based on the concept of probability. According to this recent proposal, the water table for SLS shall correspond to a recurrence period at least equal to the design lifetime of the structure, while for ULS the design water table shall represent a rare probability in the design lifetime of the structure. The value of the probability may be specified in the National Annex but a value of $1 \%$ is recommended.

\section{ANALYSIS DESCRIPTION}

The computer software PLAXIS V12.01 was used for the analysis in its two-dimensional version. A simple elasto-plastic Mohr-Coulomb constitutive soil model was used in the simulations.

The soil chosen was typical stiff clay for which traditional London Clay parameters were used. As the analysis was performed for the short term an undrained soil strength profile equal to $60+8 z$ was used (depth $\mathrm{z}$ in metres and results in $\mathrm{kPa}$ ). The water table is assumed to be the most unfavourable at the surface.
Hollow steel props with external diameter 406.4 $\mathrm{mm}$ and width $12.5 \mathrm{~mm}$ were simulated in all cases with $\mathrm{EA}=3100000 \mathrm{kN} / \mathrm{m}$.

Three different geometries were analysed: (1) cantilever with a retained height $(\mathrm{H})$ of $6 \mathrm{~m}$; (2) 4 prop wall with $\mathrm{H}$ equal to $20 \mathrm{~m}$ and embedment depth of $6 \mathrm{~m}$ and; (3) 5 prop wall with an $\mathrm{H}$ equal to $24 \mathrm{~m}$ and embedment depth of $7.5 \mathrm{~m}$. The latter two have the same system stiffness (same distance between prop levels) and therefore, allowed to verify the impact of the rest of parameters if it is assumed that systems with similar stiffness present similar strains (Long, 2001).

The parameters investigated were $\mathrm{K}_{0}$ (values of 1.0, 1.2 and 1.5) and the $\mathrm{E}_{\mathrm{u}} / \mathrm{c}_{\mathrm{u}}$ ratio $(500$ and 1,000$)$ as the two more critical parameters for wall design when using Mohr-Coulomb (Yeow \& Feltham, 2008).

The following construction sequence was modelled with an overdig of $0.5 \mathrm{~m}$ considered:

- Stage 0 Initial state conditions

- Stage 1 Wall installation and 20kPa surcharge

- Stage 2 Excavation to $-4 \mathrm{~m}$ (to $-6 \mathrm{~m}$ for the cantilever wall and end)

- Stage 3, Install strut 1

- Stage 4, 6 and 8 Excavation of $4 \mathrm{~m}$ of soil

- Stage 5, 7 and 9 Install strut

- Stage 10 Excavation to $-20 m$ (continue to $-24 m$ for the 5 props case)

\section{RESULTS}

The results of the analysis are presented below in terms of prop loads for each of the walls modelled (Figures 2-7).

\subsection{Supported wall with 4 struts}

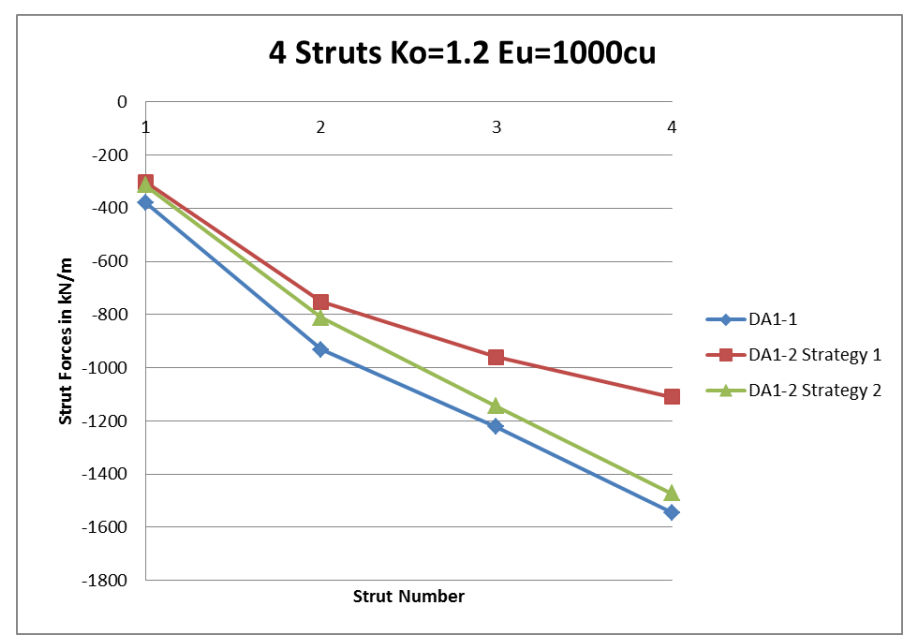

Figure 2. Deriving strut loads from different factoring strategies $\left(\mathrm{K}_{\mathrm{o}}=1.2\right.$ and $\mathrm{E}_{\mathrm{u}}=1000 \mathrm{c}_{\mathrm{u}}$ case $)$ 


\subsection{Supported wall with 5 struts}

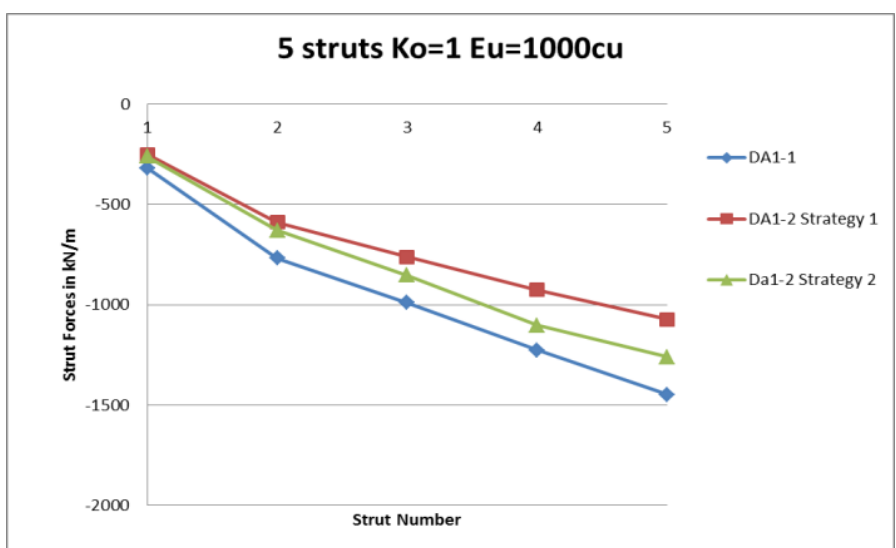

Figure 3. Deriving strut loads from different factoring strategies $\left(\mathrm{K}_{\mathrm{o}}=1\right.$ and $\mathrm{E}_{\mathrm{u}}=1000 \mathrm{c}_{\mathrm{u}}$ case $)$

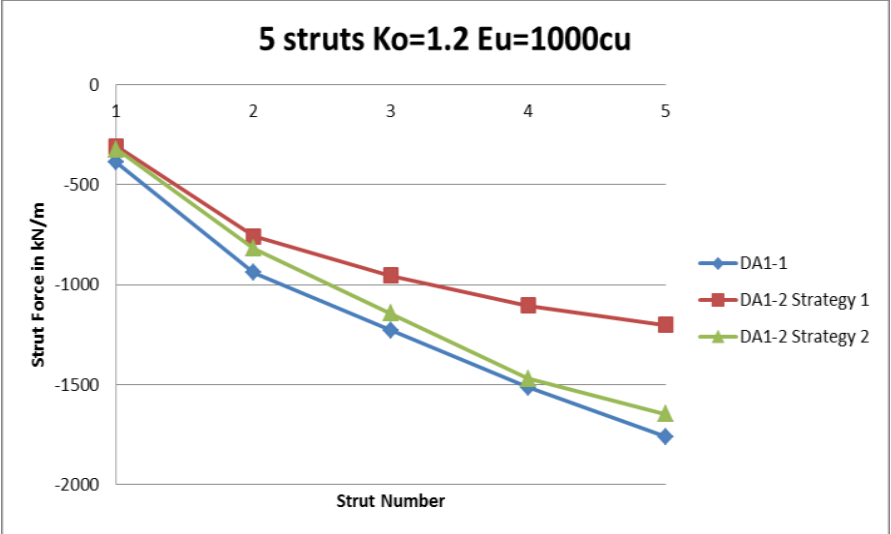

Figure 4. Deriving strut loads from different factoring strategies $\left(\mathrm{K}_{\mathrm{o}}=1.2\right.$ and $\mathrm{E}_{\mathrm{u}}=1000 \mathrm{c}_{\mathrm{u}}$ case $)$

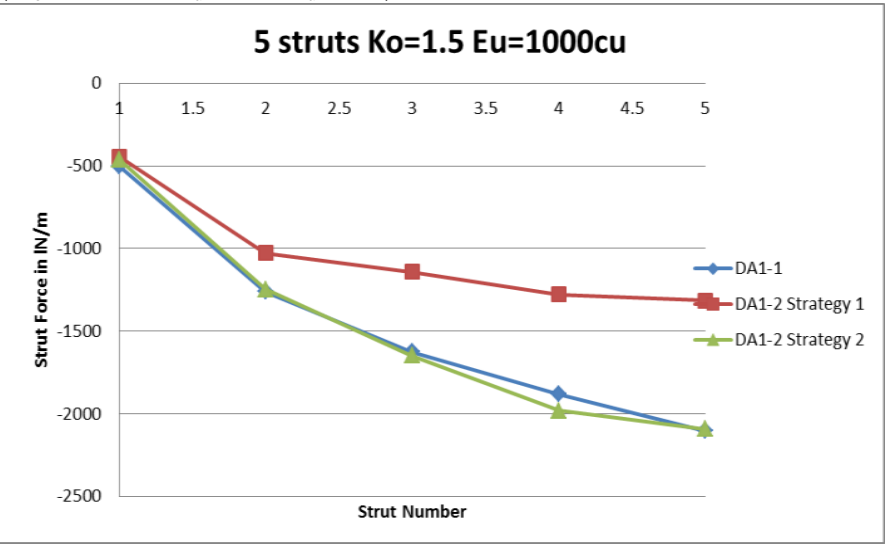

Figure 5. Deriving strut loads from different factoring strategies $\left(\mathrm{K}_{\mathrm{o}}=1.5\right.$ and $\mathrm{E}_{\mathrm{u}}=1000 \mathrm{c}_{\mathrm{u}}$ case $)$

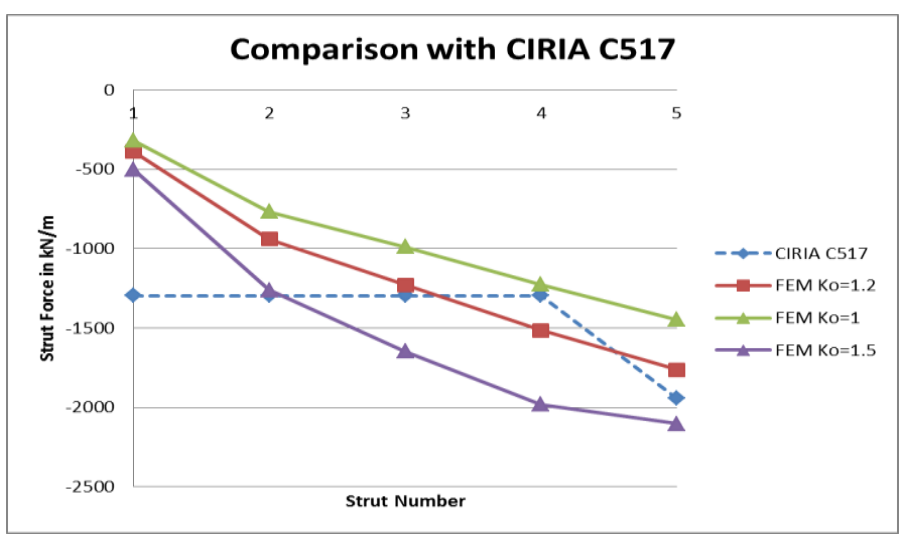

Figure 6. Comparing derived design prop loads from FEM and CIRIA for variations in $\mathrm{K}_{\mathrm{o}}$

\subsection{Reducing the soil stiffness}

Eurocode 7 does not suggest factoring soil stiffness. As stiffness is, in most cases, a parameter of high uncertainty; current practice suggests carrying out parametric analyses using upper and lower bound values. On the contrary, CIRIA C580 (Gaba et al., 2003) recommends that soil stiffness should be factored by a factor of 2 . As many designers in the UK refer to CIRIA C580 for guidance on retaining wall design, the effect of factoring the soil stiffness should be better understood. The derived prop loads are now compared for variations both in $K_{o}$ and $\mathrm{E}_{\mathrm{u}} / \mathrm{c}_{\mathrm{u}}$ ratio (see Figure 7 ).

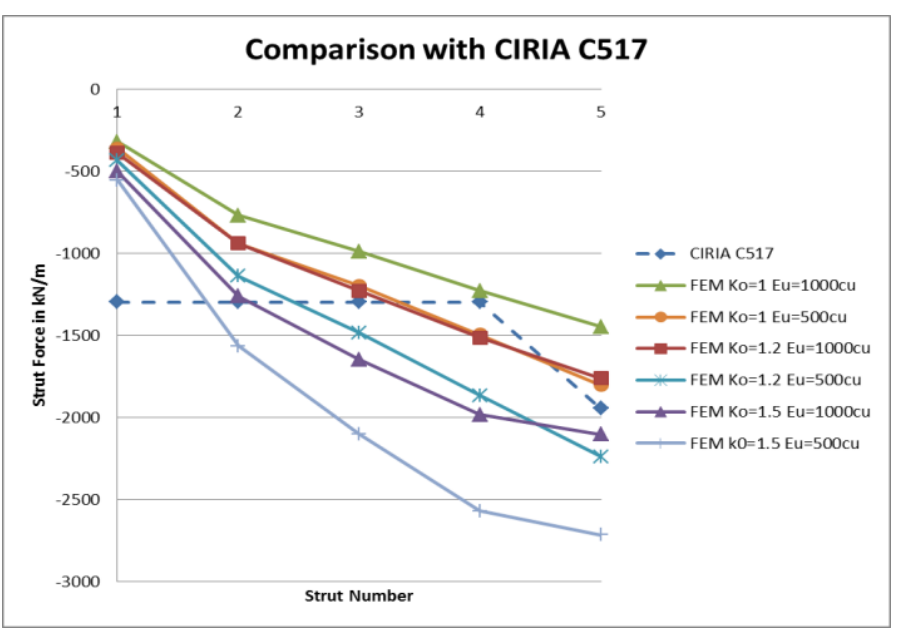

Figure 7. Comparing derived strut loads from FEM and CIRIA for variations in $\mathrm{K}_{\mathrm{o}}$ and $\mathrm{E}_{\mathrm{u}} / \mathrm{c}_{\mathrm{u}}$ ratio.

\subsection{Discussion}

\subsubsection{Comparison of different factoring strategies}

In all cases under consideration DA1-1 gives the highest values of prop forces and bending moments. The soil strength seems not to be critical for design. The divergence between DA1-2 strategies 1 and 2 of material factoring becomes more apparent as the excavation depth (and hence the number of excavation stages and props) increase with DA1-2 strategy 2 giving higher values of prop loads in all simulations (Figures 2, 3, 4 and 5). Another interesting thing is that the bending moment distribution (not presented here) is the same regardless of the number of props and the excavation depth. Unlike sheet pile walls, concrete walls are not necessarily reinforced equally on both sides or uniformly along their depth, therefore more than one bending moment might be critical to the design. Overall, as EC7 requires checks for both combinations, DA1-1 and DA1-2 strategy 2 govern the design for the material properties considered.

A further advantage of using Strategy 2 is that Ultimate Limit States are extreme and unlikely cas- 
es. As such, driving the system to ULS from the beginning, by creating an unrealistic initial stress field (Strategy 1), might be confusive. It seems, therefore, more appropriate and intuitive for the designer to understand the concept behind the EC7 ULS design, by performing the analysis from the characteristic initial stress field and checking for these unlikely states only at discrete critical stages (Strategy 2). On the other hand, it could be attractive to use DA12 strategy 1 , as it complies with the code and gives a more economic design. Also, it only requires one sequence of calculations whereas DA1-2 strategy 2 requires an extra set of separate calculations steps for each construction stage.

\subsubsection{Numerical vs empirical methods}

Empirical and FEM calculations provide different prop force values for the geometries and materials considered. Is the apparent discrepancy because the numerical methods are inadequate, or because of the situations assumed in design (surcharge, excavation level, ground water levels, length of open excavation etc.) do not always occur in practice? Most of the analysis done to date is $2 \mathrm{D}$, i.e. it assumes that a complete level of excavation is opened before any props are inserted at that level. Usually this does not occur in practice. So if 2D analysis over-predicts strut forces, would it also be true of 3D?

How good is the C517 assessment that the force in the top strut will be equal to that in lower struts? Again, sequence of excavation, as discussed before, would be important. If you do a very non-2D excavation at an early stage, you can get the top strut in with very little wall displacement, and it then picks up a lot of load.

This leads to the following questions relevant to EC7:

- Is it appropriate to use results of FEM to derive design strut loads?

- Why (if it is true) are computed values (sometimes/usually/always) greater than measured values? Can/should anything be done to amend this? (For example, Roscoe and Twine (2010) found that they had to reduce strut stiffness by about $50 \%$ to recover the measured values on one project. Is there any justification for this?)

- What sort of soil models must be used to get results appropriate for design?

- Are there any dangers of under-estimating strut loads, which could be dangerous? A particular issue for struts is that there behaviour is quite often brittle, so it could be dangerous to under-design them.

\section{CONCLUSIONS}

While a much broader study is needed, some useful conclusions can be drawn from the work done in this article:

- DA1-2 Strategy 2 gives higher values of prop loads than Strategy 1 in all these cases.

- Increasing $\mathrm{K}_{\mathrm{o}}$ values will make DA1-2 Strategy 2 to become more onerous, in terms of prop loading, than DA1-1.

- DA1-1, in most cases, governs the design of the props for the material and geometries considered, especially for lower degrees of overconsolidation (exemplified by the lower value of $\mathrm{K}_{0}$ ) and where the strength of the soil is not critically important for the design.

- The authors favour factoring at discrete stages (i.e. DA1-2 Strategy 2) for two main reasons: (1) it seems to be more critical in most cases and (2) it seems a more intuitive way of using the code than Strategy 1 where it may lead to confusion but also because it can be easily be applied in conjunction with SLS checks.

- The choice of Strategy, for deriving wall bending moments, is less important than for strut forces: this is because walls can usually display some plasticity and redistribute bending moment if it is high at some point, whereas DA1-2 strategy 2 is attractive for deriving strut forces because struts can be brittle, and DA1-2 strategy 1 might underestimate them.

- Empirical and FEM calculations provide different prop force values: Reasonable variations in $\mathrm{K}_{\mathrm{o}}$ and soil stiffness can significantly affect design prop loads derived from FEM.

- In all these cases, FEM results in lower values of strut forces at the top of the wall, increasing with excavation depth. Note that there is not much difference in the total force supporting the wall in the two cases - about $8.5 \%$.

\section{ACKNOWLEDGEMENTS}

The authors gratefully acknowledge the support of the project partners, EPSRC, Arup and European Institute, University College of London.

\section{REFERENCES}

BS EN 1997-1, Eurocode 7 - Geotechnical design, Part 1 - general rules. (2004). London: British Standards Institution. 
Bauduin, C., DeVos, M., \& Simpson, B. (2000). Some Considerations on the Use of Finite Element Methods in Ultimate Limit State Design. LSD 2000 International Workshop on Limit State Design in Geotechnical Engineering Melbourne, Australia.

Code of practice for earth retaining structures, BS 8002. (1994). London: British Standards Institution.

Gaba, A. R., Simpson, B., Powrie, W., \& Beadman, D. R. (2003). Embedded retaining walls - guidance for economic design. CIRIA Report C580, (p. 390). London: CIRIA.

Long, M. (2001). "Database for Retaining Wall and Ground Movements due to Deep Excavations." J. Geotech. Geoenviron. Eng., 127(3), 203-224.

Peck, R. B. (1969). Deep excavations and tunnelling in soft ground. 7th Int. Conf. SMFE. Mexico City. State-of-the-art vol., 225-290.

Potts, D.M, \& Zdravkovic, L. (2012). Accounting for partial material factors in numerical analysis,. Géotechnique, 62, 1053-1065.

Roscoe, H., \& Twine, D. (2010). Design and performance of retaining walls. Proceedings of the ICE - Geotechnical Engineering, Volume 163, Issue 5.

Schweiger, H. F. (2005). Application of FEM to ULS design (Eurocodes) in surface and near surface geotechnical structures. Proc. 11th Int. Conf. Computer Methods and Advances in Geomechanics, Patron Editore, Bologna, 4, 419430.

Simpson, B. (2007). Approaches to ULS design The merits of Design Approach 1 in Eurocode 7. ISGSR2007 First International Symposium on Geotechnical Safety \& Risk pp 527-538. Shanghai Tongji University, China.

Simpson, B. (2012). Eurocode 7 - fundamental issues and some implications for users, Keynote Lecture. Proc Nordic Geotechnical Meeting 2012, DGF Bulletin 27.

Simpson, B., \& Driscoll, R. (1998). Eurocode 7 - a commentary. Watford, UK: Construction Research Communications Ltd.

Simpson, B., \& Hocombe, T. (2010). Implications of modern design codes for earth retaining struc- tures. Proc ER2010, ASCE Earth Retention Conference 3, Seattle, Aug 2010.

Simpson, B., \& Junaideen, S. M. (2013). Use of Numerical Analysis with Eurocode 7. 18th Southeast Asian Geotechnical \& Inaugural AGSSEA Conference, Singapore Leung, Goh \& Shen (eds).

Simpson, B., Vogt, N., \& Van Seters, A. J. (2011). Geotechnical safety in relation to water pressures. Proc 3rd Int Symp on Geotechnical Safety and Risk, Munich.

Simpson, B., \& Yazdchi, M. (2003). Use of finite element methods in ultimate limit state design. LSD 2003: International workshop in Limit State Design in Geotechnical Engineering Practice, Cambridge, Massachusetts.

Terzaghi, K., \& Peck, R. B. (1967). Soil mechanics in engineering practice (2nd edition). New York: J. Wiley and Sons.

Twine, D., \& Roscoe, H. (1999). Temporary propping of deep excavations-guidance on design, CIRIA C517. London: CIRIA.

Yeow, H., \& Feltham, I. (2008). Case histories back analyses for the application of the Observational Method under Eurocodes for the SCOUT project. 6th International Conference on Case Histories in Geotechnical Engineering. 